\title{
Transforming Your Library Outreach with Your Patron Base in Mind
}

Erin Merrill

Westminster College

\begin{abstract}
Librarians falling short in their outreach efforts can improve by examining their assumptions
of their patron base, learning more about their campus community, being open to the need for revision and by welcoming feedback from your population. This column explores the true importance of knowing the library's users and how doing so can make for successful outreach. Examples of outreach materials are included.
\end{abstract}

Keywords: library outreach, academic libraries, patron relations

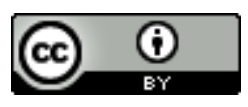

This is an Open Access article distributed under the terms of the Creative Commons Attribution 4.0 International License (http://creativecommons.org/licenses/by/4.0), which permits unrestricted use, distribution, and reproduction in any medium, provided the original work is properly cited. 
In January of 2018 I started my first job as a professional librarian as the Instruction \& Outreach Librarian at Westminster College in Salt Lake City, Utah. The library had been without an Outreach Librarian for over 3 years which meant there weren't consistent programs and outreach approaches for me to take over and learn from upon starting the position. In addition, I had received little to no training on outreach from my time in my Master's in Library and Information Science program. As such, I was given an opportunity to innovate what outreach means at our library; I was excited to get started but knew l'd need to fill some gaps in my training. Yet, with my time as a student in my rearview mirror and some overconfidence that my youthful age would help in my outreach efforts, I assumed that I knew what college students wanted and therefore, outreach would be natural and easy for me. After all, as a twenty-something myself, I should know what other twenty-somethings want, right?

It wasn't long however, before I found myself humbled. In my first semester, I held several destressing activities for students including a meditation event, a music study room, a "TV break" with snacks, and a collective "stress scream." For two of the events, not a single person showed up. For the meditation activity, four students showed up but two of them were student employees on the clock and one was my husband, so nothing to be proud of. For the collective "stress scream" we got six students - without connection to me or the library - which felt like an improvement but in reality, wasn't the picture of success that I had envisioned. Several times, I also tried tabling in the student life building only to return to the library with untouched swag and a lot of candy.

I found myself frustrated, embarrassed, and confused. What was going on? Why weren't students interested in my attempts to reach them? Was I really that out of touch with what students want? As I reflected on my outreach endeavors, I came to the realization that I was approaching students at Westminster as if they were the students at my alma mater. I hadn't taken any time to get 
to know the students at Westminster or their interests, needs, or desires. As a result, my approaches were designed for a completely different campus community which led to failed outreach. Here's a few incorrect assumptions that I was making about students at Westminster:

- Like students at my alma mater, students at this campus will always stop for free candy (wrong)

- All students like to stop and talk to strangers at booths (even more wrong)

- Students are equally interested in library events and services as I am (wrong) Ultimately, I was wrong and needed to take a step back and examine what students at this campus need, want, and deserve. I needed to reinvent my approach, learn the campus culture, and innovate an outreach program with the students in mind.

To do this, unsurprisingly, I had to leave the library walls. Fortunately, one of the great things about working at an academic institution is that there are many departments, offices, and student groups working to grab student attention. This meant that by simply walking around campus, I could quickly discover a plethora of others' outreach efforts. This allowed me to observe what students stop for, are intrigued by, and conversely, what they're bored with. Ultimately, by observing what others did, I saved myself an immense amount of time from experimenting with efforts on my own. While it is good to be creative, it was equally beneficial to borrow what already works from others. This also helped me get an understanding of other existing groups on campus which has since lead to collaborations with Westminster's Student Government, our campus "Sex Positive Week," and the campus Writing Center.

After a few afternoons walking around campus, I learned that students at Westminster prefer dry goods such as highlighters, pens, and stickers over candy. While our students will stop for candy, 
they won't stop if the candy means getting a sales pitch from someone. However, getting a pitch on a service or resource is worth stopping for if the reward is something more substantial such as fruit, Clif Bars, or a favorite drink. On our campus, if you can't offer something more substantial (budgets often make this hard) it's better to try a more passive outreach approach that doesn't require human interaction.

With these discoveries, I added a few new strategies to my outreach approach. For example, we had one of our student employees design a sticker for the library. The only guidelines I provided for the sticker were 1) it needed to include the name of the library and 2) it needed to stay within certain dimensions. I really wanted our student employee to feel free to create whatever students would like most and felt that over-directing her process would strip her from her ability to be creative.

While stickers aren't a new or innovative product, even to our library, the idea that a student could design a sticker was new for our library and produced a product that was more unique and personalized for our campus. Our student employee did an outstanding job and within a week or two we saw our sticker plastered on water bottles, laptops, notebooks and more. It also worked to create a sense of pride from our student employee and our tight knit campus often exclaimed how cool it was that one of their peers designed the sticker. Perhaps best of all, the stickers were just as affordable as bulk candy but peaked greater student interest and have a longer-lasting shelf life.

We also started putting out promotional items without a person. For example, we put out bookmarks with information about library services, printed help guides, and Giovale Library swag on a table without anyone staffing it. While this goes against all my instincts as an extrovert, I reminded myself that I am not the target audience. Having unmanned tabling stations allows students to walk up and take what they please without feeling intimidated. Usually we'll put up a table near the library 
entrance and leave it up for a short period of time, about a week or so. The fact that the table is usually there draws their attention and the material does the rest. While I haven't totally abandoned personally handing out promotional items or sitting at tabling events, I've come to learn that by taking multiple approaches, the library is likely to reach a greater number of students.

I still wanted to offer students ways to de-stress and after learning their tendencies, I changed our in-person events to more passive de-stress activities such as community word searches, coloring pages, and grab-and-go stress balls. Approaches like this have been very well received with high participation from our students. Being open to revising or changing a failed event or outreach attempt is key to creating outreach that is welcomed by your community. While my original de-stress events might have appeared more proactive as an Outreach Librarian, they weren't serving the needs of our students. As we look to create events, activities, or resources for our campus, it's important that we understand what our community will engage with and is interested in.

Next, I observed our students' social media behaviors. While our library had a Facebook page, a quick conversation with our student employees helped me discover that Generation Z students (the vast majority of our student population) don't use Facebook and are more prone to use Twitter, Snapchat, and Instagram. To start, I decided to just focus on just one new social media platform and determined to create a Giovale Library Twitter page. In the beginning, I followed other pages from Westminster and any user who used the campus hashtag. I also followed students with Westminster College (or any of its various nicknames) in their bio and then quietly observed my new Twitter feed. This helped me determine our students' sense of humor which is quick, witty, and a bit snarky. I followed their lead when tweeting on the library account and the followers started coming. While we 
have less than 200 followers, in comparison to other academic libraries, our ratio of students to followers is on par.

While our social media following is small with room to grow, when examining both our Facebook page and Twitter page user insights, we regularly get more views, engagements, and exposure on Twitter than we do Facebook. This can likely be attributed to the fact that our students typically use Twitter more often and appreciate the informal nature of the platform-a fact only discovered by talking to our students. While we won't abandon our Facebook page or our more traditional promotional material (printed flyers, emails, etc.), Twitter helped our library recognize that communication is always evolving and that we can always be on the lookout for new ways to reach our students.

It also helped us discover that promoting the library doesn't always mean you have to promote a service or resource from the library. It can mean engaging with your users, participating in online conversations, or providing a quick second of entertainment. Creating new, witty, or informal content on Twitter helps paint the library as a welcoming and fun place to be. In an effort to grow our followers, we include our Twitter handle and Facebook page on each issue of our bathroom newsletter, The Giovale Gazette, and offer the occasional Twitter giveaway.

Learning our student humor from Twitter encouraged me to re-examine some of our other promotional materials such as our table-tent and study carrel flyers. While several students have told me they typically don't look at flyers, they also assured me that they will read flyers if they're eye catching. And, thanks to my time on Twitter, I knew just what would catch their eye: library memes. I must confess, I was nervous to create memes and even more nervous to test them out on our student employees. Despite my fear, I created over 20 memes that promoted the library, its resources, and our 
Research Help services. I then spent several afternoons testing them out with our student employees.

One by one, I showed them the memes and gathered feedback. With some memes they laughed right away which was a great indicator that the meme was a keeper. Other memes were met with blank stares and an "I don't get it" which helped me quickly eliminate those ones. I even had a few students quickly create and email me their own memes, several of which I've used.

These memes are now in the table tents on our study tables and posted in each study carrel. I keep catching students stopping to read the memes which is something I hadn't seen in my previous semesters here at the Giovale Library. It has also provoked conversations with students and campus staff and faculty about Google. While the memes may jab at Google, they allow us to talk with the campus community about how to use Google effectively and how there's other resources that may benefit their needs. More than anything, they get students to stop, read the flyer and discover they can get help in the library. However, had I not taken the time to first gauge student interests and second test my efforts on a small pool of students, l'd likely continue to create flyers with a more professional design. Doing so would have kept me in my comfort zone but destined the flyers to be ignored.

While the memes are eye-catching and exciting now, in a few months' time they will become "old content" and get ignored by our students. So, moving forward, I'm learning how to reinvent the wheel with traditional signage and am constantly asking myself, "How can I make this flyer stand-out? Would a student stop to read this? And is this different from what they've seen before?" Currently we're trying to combine print media with 3D objects to promote our 3D printer. This brings our fliers to life and moves our outreach attempts forward by introducing new ideas to our promotional material. Sometimes all it takes to be innovative is switching up your routine work or materials with a new color, format, or in this case, a 3D stick figure. 
I now try to involve students in most of my outreach efforts. For example, instead of creating a "Welcome Back" banner to hang in the library by myself, I found an artistic student who knows what would make students look up. When it comes to buying food for finals week, I ask studying students what they're craving, student employees what food would make them happiest, and I even put out a call for food suggestions in our newsletter and on social media pages. Several students emailed me their requests or tweeted at the library with their dream food list as a result. When finals rolled around, the students who made request were overjoyed to see their request were met. Following through on this promise proved to create unofficial library ambassadors who promoted our library to their friends and peers purely because they were happy with the library's efforts. While seeking student input creates an additional step on my part, it pays to give students what they want. Similarly, when feeling unimaginative or unable to create something new for the library, the students act as never ending well of new ideas.

One of the biggest difficulties I face in meeting student needs however, is a limited outreach budget. To deal with financial restraints, we get creative in how we go about offering outreach. For example, our library always offers free study snacks to students during finals week. In the past we could buy very little food and it would go by very quickly thus only serving a small portion of our students. To bolster our offerings, we sought out businesses such as Einstein Bros. Bagels who donate their end-of-day bagels to us. All it costs us is the time it takes to pick up the bagels but otherwise we are able to put out hundreds of bagels for students to enjoy at no-cost to us. Similarly, instead of buying pre-packaged goods, we take advantage of the campus popcorn machine. For $\$ 30$ dollars we can pop over 1000 bags of single-served popcorn which allows us to hand out food to more students than if we bought $\$ 30$ worth of pre-packed chips. 
Each October we transform our library to resemble Hogwarts in what our campus has come to love and know as Hogwarts Halloween. However, Harry Potter décor does not come cheap, so our library has worked hard to create our own decorations. Instead of buying items from name brand, we look up DIY tutorials to create wands, broomsticks, flying keys and so much more. You'd also be surprised by how much you can do with crate paper and a creative mind. We've even made several runs to the local Goodwill Industries and upcycled donated items. We know how to maximize our resources and utilize the creative minds of our staff and student employees to produce big outcomes with little funds.

Starting a job with little training allowed me to innovate what outreach looked like in our library. I am continually learning and look forward to implementing an outreach assessment plan to discover how to improve my outreach efforts. In the meantime, I have discovered that leaning on your experience as a student is not enough and that to create outreach for your campus, you must learn about your community, be open to revising failed attempts, welcome student ideas, and push yourself to think outside of your routine work. If we can dive out of our comfort zones and grow from our mistakes, librarians will learn how to create and implement meaningful outreach in their library. 